\title{
Ensino remoto emergencial nas instituições de ensino superior e as tecnologias adotadas: uma revisão integrativa
}

\author{
Emergency remote education in higher education institutions and adopted \\ technologies: an integrative review
}

\author{
Ednaene de Menezes \\ Mestranda em Ciência da Informação \\ Universidade Federal do Ceará - UFC. \\ Fortaleza, Ceará - Brasil. \\ ednaenedemenezes@gmail.com \\ Andréa Soares Rocha da Silva \\ Doutora em Educação \\ Universidade Federal do Ceará - UFC. \\ Fortaleza, Ceará - Brasil. \\ andreasrs07@gmail.com
}

\begin{abstract}
Resumo: O objetivo da pesquisa foi analisar o ensino remoto emergencial e o uso das tecnologias que o viabilizam nas Instituições de Ensino Superior, no contexto da pandemia da Covid-19. Norteou-se pela seguinte questão: como se caracterizam as estratégias didáticas e os recursos educacionais digitais utilizados no ensino remoto emergencial nas Instituições de Ensino Superior nessa pandemia? A metodologia adotada foi a revisão integrativa de literatura com buscas nas bases SciELO e Google Scholar. Caracterizou-se as estratégias didáticas, as plataformas e os recursos educacionais digitais utilizados. Constatou-se o desenvolvimento do letramento digital de professores e alunos e a autonomia discente, bem como a sobrecarga de trabalho e a ansiedade gerada pelas incertezas e o sentimento de inadequação. Conclui-se que o ensino remoto emergencial tem sido um dinâmico e ao mesmo tempo desafiador modelo educacional para as Instituições de Ensino Superior e para seus professores e alunos.
\end{abstract}

Palavras chave: ensino remoto emergencial; recursos educacionais digitais; tecnologias digitais da informação e comunicação.

Abstract: The objective of the research was to analyze emergency remote teaching and the use of Technologies that make it feasible in Higher Educations Institutions, in the contexto of the Covid-19 pandemic. It was guided by the following question: how are the didatic strategies and digital educational resources used in emergency remote teaching in Higher Education Institutions characterized in this pandemic? The methodology adopted was na integrative literature review with searches in the SciELO and Google Scholar databases. The didactic strategies, platforms and digital educational resources used were caracterized. It was verified the development of digital literacy of teachers and students and students autonomy, as well as work overload and anxiety generated by uncertainties and the feeling of inadequacy. It is concluded that emergency remote teaching has been a dynamic and, at the same time, challenging model of teaching for Higher Education Institutions and for their teachers and students.

Keywords: emergencial remote teaching; digital educational resurces; digital information and communication technologies.

\section{Cite como}

\section{(ABNT NBR 6023:2018)}

MENEZES, Ednaene; SILVA, Andréa Soares Rocha. Ensino remoto emergencial nas instituições de ensino superior e as tecnologias adotadas: uma revisão integrativa. Dialogia, São Paulo, n. 40, p. 1-19, e20579, jan./abr. 2022. Disponível em: https://doi.org/10.5585/40.2022.20579. 


\section{Introdução}

Desde que a Organização Mundial da Saúde caracterizou, em 11 de março de 2020, o estado de pandemia do vírus da Covid-19, todos os setores da sociedade têm sido afetados, inclusive a área educacional. Medidas sanitárias têm sido adotadas pela OMS, governos, estados e municípios e a população mundial. Para a comunidade educacional, a medida urgente a ser tomada foi a suspensão das aulas presenciais em março de 2020 em todo o país.

Porém, os calendários escolares e acadêmicos precisavam avançar, evitando, assim, que o período letivo fosse perdido. A princípio, a solução encontrada tinha sido um novo formato de ensino em substituição ao modelo presencial, o qual passou a ser chamado por algumas instituições de Ensino Remoto Emergencial. Esse modelo, para ser posto em prática, depende do uso das Tecnologias Digitais da Informação e Comunicação para que os processos de ensino e de aprendizagem possam ser realizados (SCHNEIDER et al., 2020).

Esta pesquisa tem como objetivo analisar o formato de ensino remoto emergencial e o uso das TDIC que o viabiliza. A metodologia adotada para alcançar esse objetivo foi a revisão integrativa de literatura, que em seu primeiro passo teve a seguinte questão norteadora para responder: Como se caracterizam as estratégias didáticas e metodológicas e os recursos educacionais digitais adotados e utilizados no ensino remoto emergencial nas Instituições de Ensino Superior nessa pandemia?

A relevância deste estudo se justifica pela possibilidade de identificação de aspectos da Educação a Distância $(\mathrm{EaD})$, já consolidados, que de certa forma viabilizaram a realização do Ensino Remoto Emergencial, a saber: estratégias didático-avaliativas, recursos educacionais digitais, papéis docentes, suporte das TDIC entre outros.

\section{Referencial teórico}

No último dia do ano de 2019 foi reportada ao escritório da Organização Mundial da Saúde (OMS) uma pneumonia de causas desconhecidas detectada em Wuban, capital da província de Hubei, na China. Um mês depois, em 30 de janeiro de 2020, o surto foi declarado como Emergência de Saúde Pública de Importância Internacional e desde então toda a Humanidade tem sofrido as consequências com o até aquele momento desconhecido e letal vírus. (WHO, 2020).

No Brasil, o Ministério da Saúde editou a Portaria $n^{\circ}$ 188, de 3 de fevereiro de 2020, declarando Emergência em Saúde Pública de Importância Nacional, em razão da infecção humana pelo novo Coronavírus (2019-nCoV), considerando ser este um evento complexo e que a situação 
demandava o emprego urgente de medidas de prevenção, controle e contenção de riscos, danos e agravos à saúde pública (BRASIL, 2020e).

O governo federal sanciona a Lei no 13.979 de 06 de fevereiro de 2020, que dispõe sobre as medidas para enfrentamento da emergência de saúde pública de importância internacional decorrente do coronavírus, responsável pelo surto de 2019. Nessa lei, aparece pela primeira vez a sugestão de medidas a serem tomadas para o enfrentamento da emergência de saúde pública de importância internacional, a exemplo de isolamento, quarentena e uso obrigatório de máscaras de proteção individual em território brasileiro (BRASIL, 2020f).

A caracterização de pandemia foi declarada pela OMS em 11 de março de 2020, uma vez que a disseminação comunitária da Covid-19 estava em todos os continentes. Como forma de contê-la, a mesma OMS recomendava três ações básicas: isolamento e tratamento dos casos identificados, testes massivos e distanciamento social. (WHO, 2020).

O Ministério da Educação por meio da Portaria no 544 de 16 de junho de 2020 dispôs sobre a substituição das aulas presenciais por aulas em meios digitais, enquanto durar a situação de pandemia do novo coronavírus - Covid-19, e revogou as Portarias MEC no 343, de 17 de março de 2020, no 345, de 19 de março de 2020, e no 473, de 12 de maio de 2020, que dispunham no mesmo sentido (BRASIL, 2020c).

A partir desse momento, governos estaduais e municipais editaram decretos e outros instrumentos legais e normativos para o enfrentamento da emergência de saúde pública, estando, dentre essas medidas, a suspensão das atividades escolares.

Em 18 de março de 2020, o Conselho Nacional de Educação (CNE) veio a público elucidar aos sistemas e às redes de ensino, de todos os níveis, etapas e modalidades, considerando a necessidade de reorganizar as atividades acadêmicas por conta de ações preventivas à propagação da Covid-19. Assim, por intermédio do Parecer CNE/CP nº 5/2020 este conselho conduziu algumas recomendações à educação superior, dentre elas, a substituição de disciplinas presenciais por aulas não presenciais com a utilização das TDIC, incluindo as mídias sociais (BRASIL, 2020d).

A Medida Provisória no 934 , de $1^{\circ}$ de abril de 2020, que teve seu texto base aprovado pela Câmara dos Deputados, foi convertida na Lei no 14.040, de 18 de agosto de 2020, estabelecendo as normas educacionais excepcionais sobre o ano letivo da educação infantil, da educação básica e do ensino médio e superior durante o estado de calamidade pública (BRASIL, 2020g; 2020h).

Diante desse exposto normativo, percebe-se que o contexto da pandemia trouxe consigo uma mudança abrupta que foi a substituição das aulas presenciais por aulas remotas mediadas pelas tecnologias. Segundo Schneider et al. (2020) essa prática foi nomeada por algumas instituições 
como "Ensino Remoto Emergencial" por se tratar de um ensino alternativo em momento de crise sanitária (HODGES, 2020; BEHAR, 2020; ORTEGA, 2020).

O Ensino Remoto Emergencial traz similaridades fortes com a Educação a Distância (EaD), porém, não significa que devam ser usados como termos sinônimos. São formatos de ensino que diferem entre si. A Educação a Distância é definida como

[...] modalidade educacional na qual a mediação didático-pedagógica nos processos de
ensino e aprendizagem ocorra com a utilização de meios e tecnologias de informação e
comunicação, com pessoal qualificado, com políticas de acesso, com acompanhamento
e avaliação compatíveis, entre outros, e desenvolva atividades educativas por estudantes
e profissionais da educação que estejam em lugares e tempos diversos. (BRASIL, 2017).

Percebe-se, portanto, que a EaD possui normativas e organização próprias, além de um minucioso processo de planejamento para sua implementação. Por outro lado, o Ensino Remoto Emergencial foi normatizado para atender um estado de exceção na Educação, isto é, passou a existir para atender a uma emergência (ALVES, 2020; SALDANHA, 2020; MOREIRA; SCHLEMMER, 2020; SILVA; ANDRADE; BRINATTI, 2021; BERNARDO; MAIA; BRIDI, 2020; HOFFMAN, 2020).

Há, porém, quem advogue serem estas modalidades equivalentes, como João Mattar, em uma entrevista concedida em julho de 2020, na qual afirmou que "o ensino remoto é EaD" (MATTAR, 2020, p.6). Sua justificativa para tal afirmação é a de que o ensino remoto emergencial e a EaD seriam coisas distintas a princípio, porém, no momento atual as instituições, bem ou mal, já teriam tido tempo hábil para realizar o planejamento e adaptações que a EaD exige. Todavia, discordamos, pois isto não muda o fato de que o Ensino Remoto Emergencial está sendo implementado por cursos presenciais, sujeitos a normativas e regulamentações próprias ao ensino presencial, funcionando como tal apenas como condição de exceção. Ademais, os critérios de avaliação oficiais do MEC para cursos de EaD por certo não se aplicarão a esses casos.

Apesar disto, as similaridades entre o Ensino Remoto Emergencial e a EaD são inquestionáveis. As aulas remotas são viabilizadas por intermédio das tecnologias e estas por sua vez conduzem às ferramentas e/ou plataformas digitais que serão responsáveis pelo ensino e aprendizagem. As TDIC exercem um papel fundamental por possibilitar: a realização de encontros educacionais; a comunicação e interação entre professores e alunos e entre alunos; o compartilhamento de recursos educacionais digitais multimidiáticos. Portanto, as interseções entre ambas as modalidades são evidentes (OSÓRIO, 2020; MARTINS, 2020; MOREIRA; HENRIQUES; BARROS, 2020; RITTER; PERIPOLLI; BULEGON, 2020; OLIVEIRA; MENDONÇA; SILVA, 2020). 
De qualquer forma, convém considerar que o simples acesso às TDIC não significa necessariamente que o ensino e a aprendizagem terão sucesso e êxito imediato nessas modalidades. Por outro lado, precisa-se considerar que o perfil do aluno do Ensino Remoto Emergencial é diferente do perfil do aluno da EaD, por razões de domínio tecnológico, letramento digital e, principalmente, de infraestrutura, como já mencionado.

\section{Percurso metodológico}

Para o desenvolvimento desta pesquisa adotou-se a revisão integrativa da literatura, por ser uma metodologia que proporciona a síntese do conhecimento e a incorporação da aplicabilidade de resultados de estudos significativos. Além disso, incorpora um vasto leque de propósitos, tais como: a definição de conceitos, a revisão de teorias e evidências, bem como a análise de problemas metodológicos (SOUZA; SILVA; CARVALHO, 2010).

A revisão integrativa seguiu seis passos: o estabelecimento da hipótese ou questão de pesquisa; a amostragem ou busca na literatura; a categorização dos resultados; a avaliação dos estudos incluídos na revisão; a interpretação dos resultados; e a síntese do conhecimento ou apresentação da revisão. (MENDES; SILVEIRA; GALVÃO, 2008). O primeiro passo dessa pesquisa se deu a partir da seguinte questão norteadora: Como se caracterizam as estratégias didáticas e metodológicas e os recursos educacionais digitais adotados e utilizados no ensino remoto emergencial nas Instituições de Ensino Superior nessa pandemia?

Para responder a essa pergunta inicial, buscou-se caracterizar as estratégias e recursos didáticos utilizados no ensino remoto, quanto às suas ferramentas de criação, suas plataformas de compartilhamento e formas de preservação. O passo seguinte foi a busca na literatura por artigos científicos que abordassem essa temática. A busca foi realizada em duas bases de bases de dados: Scientific Electronic Library Online (SciELO) e Google Scholar. A escolha destas bases de dados se deu pelo fato de serem abertas, possuírem e disponibilizarem um acervo de publicações bastante atuais, facilitando o acesso às publicações recentes que retratassem a realidade brasileira no contexto estudado.

Durante as buscas realizadas nas bases de dados optou-se por aplicar os filtros das próprias plataformas, os quais foram: na SciELO: coleções: Brasil; ano de publicação: 2020/2021; áreas temáticas: todas; tipo de literatura: todos. Na Google Scholar classificar por relevância; classificar por data; em língua portuguesa; a qualquer momento. Foram utilizados também os operadores booleanos "OR" e " $A N D$ " para auxiliar no processo de inclusão e "NOT" para o processo de exclusão. 
Os descritores aplicados na execução da busca dos estudos foram: (“ensino remoto emergencial” $O R$ “ensino remoto" OR “ensino emergencial” OR “ensino online” OR "educação online") AND ("pandemia" OR tempos de pandemia" OR “Covid-19” OR “coronavírus"). Aplicouse essa estratégia de busca completa e também combinando os termos em pares, com os operadores OR e $A N D$.

Como critérios de inclusão, consideraram-se elegíveis artigos originais que respondessem à questão norteadora no idioma português, com publicação completa e resumos disponíveis e indexados nas bases de dados, que tivessem sido publicados no recorte temporal 2020/2021 e que tivessem relação com o Ensino Remoto Emergencial e a pandemia de Covid-19.

$\mathrm{Na}$ base SciELO foram excluídos artigos que não apresentavam relação com o ensino remoto emergencial em tempos de pandemia de Covid-19. Na Google Scholar, foram excluídos TCC, teses, dissertações, editoriais, além de artigos que não apresentavam relação com o ensino remoto emergencial em tempos de pandemia de Covid-19.

O terceiro passo foi a categorização dos estudos. A busca realizada resultou num quantitativo de 20 artigos encontrados na SciELO e de 5.810 na Google Scholar. Após a adoção dos critérios de exclusão restaram 22 artigos que compõem a revisão integrativa desta pesquisa. Esses 22 artigos foram lidos na íntegra e de forma sistemática, sendo a análise feita através de fichamento para a extração e organização dos dados dos artigos publicados.

Foi organizado um quadro para o fichamento dos artigos com o objetivo de melhor organizar sua coleta de dados, sendo identificadas e coletadas as seguintes informações: a) identificação dos autores e ano de publicação; b) estratégias didáticas adotadas pelos professores durante o ensino remoto; c) tipos de recursos educacionais digitais criados para o ensino remoto; d) tipos de ferramentas de produção de recursos educacionais digitais; e) plataformas adotadas para a realização de aulas remotas; e, f) formas de preservação dos recursos educacionais digitais. Tais parâmetros de categorização foram escolhidos por estarem diretamente relacionados com as questões de pesquisa definidas para o estudo, facilitando, assim, o próximo passo, de análise dos dados.

No quarto passo, que trata da avaliação dos estudos na revisão integrativa, foi realizada a análise dos dados considerando pertinência e adequação ao objeto de estudo. Já o quinto passo tratou da discussão e interpretação dos resultados, que foram comparados e fundamentados com as proposições da Organização Mundial da Saúde (WHO, 2020), do Ministério da Saúde (BRASIL, 2020e), do Ministério da Educação (BRASIL, 2020a) e do Conselho Nacional de Ensino (BRASIL, 2020d) sendo realizada uma avaliação comparativa quanto à sua aplicabilidade. 
Por fim, no sexto e último passo desse processo metodológico, foi realizada a apresentação da revisão integrativa e síntese do conhecimento, onde as informações de cada artigo revisado foram contempladas de maneira sucinta e sistematizada, comparando os achados e respondendo à questão norteadora da pesquisa.

\section{Resultados e discussão}

Foram consideradas elegíveis as publicações compreendidas a partir da entrada em vigor da Portaria no 343, de 17 de março de 2020, do Ministério da Educação, que suspendia as aulas presenciais, sendo substituídas pelo Ensino Remoto Emergencial enquanto durar a situação pandêmica (BRASIL, 2020a). O quadro 1 apresenta o resultado das buscas realizadas nas duas bases de dados pelas categorias de descritores e operadores booleanos.

Quadro 1 - Total de itens recuperados no processo de busca

\begin{tabular}{|c|l|l|}
\hline Descritores & SciELO & \multicolumn{1}{|c|}{$\begin{array}{l}\text { Google } \\
\text { Scholar }\end{array}$} \\
\hline $\begin{array}{l}\text { ("ensino remoto emergencial" OR "ensino remoto" OR "ensino emergencial” OR } \\
\text { "ensino online" OR "educação online") AND ("pandemia" OR tempos de } \\
\text { pandemia" OR "Covid-19" OR "coronavírus") }\end{array}$ & & $\begin{array}{l}\text { aproxim. } \\
5.810\end{array}$ \\
\hline
\end{tabular}

Fonte: Elaborado pelas autoras.

Como apresentado no quadro 1 , na busca inicial foram recuperados um total de 20 trabalhos na base de dados da SciELO e aproximadamente 5.810 no Google Scholar, gerando um total de 5.830 trabalhos recuperados. Ao recorrer aos critérios de exclusão, já devidamente adotados e citados na seção metodológica, chegou-se a um total de 200 artigos analisados. Em seguida, a partir da leitura de seus títulos e resumos foram excluídos mais 103 artigos, restando, agora, 97 trabalhos. Destes, restaram 10 da SciELO e 87 do Google Scholar.

Realizou-se a leitura na íntegra desses 97 artigos restantes, permitindo, desse modo, fazer um recorte da temática em questão. O recorte adotado foi a abordagem do ensino remoto emergencial no contexto das Instituições de Ensino Superior no Brasil, excluindo-se, dessa forma, artigos que abordassem o ensino remoto no exterior e o ensino remoto no contexto da educação infantil, do ensino fundamental, do ensino médio e do ensino técnico e tecnológico no Brasil e no mundo.

Após o recorte adotado, restou um total final de 22 artigos (como apresentado no quadro 2) que continham em suas pesquisas respostas para a questão norteadora deste trabalho. Ou seja, esses artigos analisados apresentaram quais foram as estratégias adotadas por professores das IES 
para atender ao Ensino Remoto Emergencial, que tipos de recursos educacionais digitais eles criaram e quais ferramentas e plataformas foram utilizadas na preparação e divulgação desses recursos e em que ambientes esses materiais estão sendo arquivados.

Dos 22 artigos que foram analisados nesta pesquisa, 5 deles são do ano de 2021 (conforme quadro 2) e os outros 17 são do ano de 2020 (conforme quadro 3).

Nos quadros 2 e 3 abaixo constam os 22 artigos divididos por ano, autores.

Quadro 2 - Artigos publicados no ano de 2021

\begin{tabular}{|l|l|l|}
\hline Ano & \multicolumn{1}{|c|}{ Autores } & \multicolumn{1}{c|}{ Título } \\
\hline 2021 & $\begin{array}{l}\text { Assis, V.L.B.; } \\
\text { Barbosa,E.P.; Reis, M.C.S. }\end{array}$ & $\begin{array}{l}\text { Mudanças no ensino em saúde: uma revisão sistemática das } \\
\text { metodologias adotadas na pandemia da Covid-19. }\end{array}$ \\
\hline 2021 & Galvão, M.C.B. et al. & $\begin{array}{l}\text { Usos de tecnologias da informação e comunicação no ensino } \\
\text { superior em Enfermagem durante a pandemia da Covid-19. }\end{array}$ \\
\hline 2021 & $\begin{array}{l}\text { Gusso, A.K.; Castro, B.C.; } \\
\text { Souza, T. }\end{array}$ & $\begin{array}{l}\text { Tecnologias de Informação e Comunicação no ensino de } \\
\text { Enfermagem durante a pandemia da Covid-19: Revisão integrativa. }\end{array}$ \\
\hline 2021 & $\begin{array}{l}\text { Oliveira, A.M.; Oliveira, } \\
\text { C.J. }\end{array}$ & $\begin{array}{l}\text { O ensino remoto durante a pandemia de Covid-19: sala de aula } \\
\text { invertida e o uso das tecnologias digitais de informação. }\end{array}$ \\
\hline
\end{tabular}

Fonte: Elaborado pelas autoras.

Quadro 3 - Artigos publicados no ano de 2020

\begin{tabular}{|l|l|l|}
\hline Ano & \multicolumn{1}{|c|}{ Autores } & \multicolumn{1}{c|}{ Título } \\
\hline 2020 & Amaral, E.; Polydoro, S. & $\begin{array}{l}\text { Os desafios da mudança para o ensino remoto emergencial na } \\
\text { graduação na Unicamp-Brasil. }\end{array}$ \\
\hline 2020 & $\begin{array}{l}\text { Arruda, J.S.; Siqueira, } \\
\text { L.M.R.C. }\end{array}$ & $\begin{array}{l}\text { Metodologias ativas, ensino híbrido e os artefatos digitais: sala de aula } \\
\text { em tempos de pandemia. }\end{array}$ \\
\hline 2020 & $\begin{array}{l}\text { Barbosa, A.M.; Viegas, } \\
\text { M.A.S.; Batista, R.L.N.F.F. }\end{array}$ & $\begin{array}{l}\text { Aulas presenciais em tempos de pandemia: relatos de experiências de } \\
\text { professores do nível superior sobre as aulas remotas. }\end{array}$ \\
\hline 2020 & $\begin{array}{l}\text { Barbosa, M.S.; Bressan Jr., } \\
\text { M.A. }\end{array}$ & $\begin{array}{l}\text { Engajamento e interatividade no ensino remoto: a sala de aula digital } \\
\text { em tempos de pandemia. }\end{array}$ \\
\hline 2020 & Boell, M.; Arruda, A.A. & $\begin{array}{l}\text { O uso das tecnologias digitais no ensino superior em tempos de } \\
\text { pandemia: relato de experiência. }\end{array}$ \\
\hline 2020 & Ferreira, L.F.S. et al. & $\begin{array}{l}\text { Uso de tecnologias no ensino superior público brasileiro em tempos de } \\
\text { pandemia Covid-19. }\end{array}$ \\
\hline
\end{tabular}




\begin{tabular}{|c|c|c|}
\hline Ano & Autores & Título \\
\hline 2020 & $\begin{array}{l}\text { Gonçalves, L.M., } \\
\text { Gambarato, V.T.S. }\end{array}$ & $\begin{array}{l}\text { A importância da tecnologia da informação e comunicação digital e } \\
\text { suas ferramentas nas aulas remotas do ensino superior durante a } \\
\text { pandemia. }\end{array}$ \\
\hline 2020 & $\begin{array}{l}\text { Limeira, G.N; Batista, } \\
\text { M.E.P.; Bezerra, J.S. }\end{array}$ & $\begin{array}{l}\text { Desafios da utilização das novas tecnologias no ensino superior frente } \\
\text { à pandemia da Covid-19. }\end{array}$ \\
\hline 2020 & Maciel, M.A.C. et al. & $\begin{array}{l}\text { Os desafios do uso de metodologias ativas no ensino remoto durante } \\
\text { a pandemia do Covid-19 em um curso superior de enfermagem: um } \\
\text { relato de experiência. }\end{array}$ \\
\hline 2020 & Medeiros, J. et al. & $\begin{array}{l}\text { Transposição do ensino presencial para o digital: desafios } \\
\text { contemporâneos em tempos de pandemia. }\end{array}$ \\
\hline 2020 & Mélo, C.B. et al. & $\begin{array}{l}\text { Ensino remoto nas universidades federais do Brasil: desafios e } \\
\text { adaptações da educação durante a pandemia de Covid-19. }\end{array}$ \\
\hline 2020 & Regueiro, E.M.G. & $\begin{array}{l}\text { Ensino mediado por tecnologias no curso de Fisioterapia do Centro } \\
\text { Universitário Barão de Mauá durante o período de pandemia da Covid- } \\
19 .\end{array}$ \\
\hline 2020 & Rosseto, L.P. et al. & $\begin{array}{l}\text { Relatos de experiências de professores do nível superior no processo } \\
\text { de ensino-aprendizagem durante a pandemia Covid- } 19 \text {. }\end{array}$ \\
\hline 2020 & $\begin{array}{l}\text { Silus, A.; Fonseca, A.L.C.; } \\
\text { Jesus, D.L. }\end{array}$ & $\begin{array}{l}\text { Desafios do ensino superior brasileiro em tempos de pandemia da } \\
\text { Covid-19: repensando a prática docente. }\end{array}$ \\
\hline 2020 & Silva, C.C.F.; Freitas, L.G. & $\begin{array}{l}\text { Remoto, mas não distante: a reinvenção do ensino na Educação } \\
\text { Superior em tempos de Covid-19. }\end{array}$ \\
\hline 2020 & Valente, G.S.C. et al. & $\begin{array}{l}\text { O ensino remoto frente às exigências do contexto de pandemia: } \\
\text { reflexões sobre a prática docente.. }\end{array}$ \\
\hline
\end{tabular}

Fonte: Elaborado pelas autoras.

A partir deste momento serão apresentados e discutidos os dados que foram devidamente tabulados dos 22 artigos aqui estudados. Serão apresentadas as estratégias didáticas e metodológicas, os tipos de recursos educacionais, as plataformas e as formas de preservação adotadas pelos professores no ensino remoto.

\subsection{Estratégias adotadas para o ensino remoto emergencial}

Os processos de ensino e de aprendizagem precisaram ser reinventados nesse tempo de pandemia, por conta do distanciamento social e implantação do ensino remoto. A preparação de planos de ensino emergencial começou a surgir, assim como a viabilização de novas formas de avaliação e de mediação em ambiente virtual, bem como treinamentos para desenvolver competências digitais e a reorganização de aulas práticas e de laboratório. Assim, toda a área Educacional começou a buscar soluções para atender e se adequar ao ensino remoto emergencial. (AMARAL; POLYDORO, 2020; GUSSO; CASTRO; SOUZA, 2021). 
Novos formatos de estratégias de ensino e de aprendizagem começaram a ser adaptados ao ensino remoto, em especial as metodologias ativas com atividades que demandam proatividade, onde o aluno exerce papel central no aprendizado, agora de forma remota. Segundo a revisão integrativa realizada, as principais metodologias ativas adotadas no ensino remoto emergencial foram: a Aprendizagem Baseada em Conhecimentos Básicos (ASSIS; BARBOSA; REIS, 2021); Aprendizagem Baseada na Pesquisa; Aprendizagem Baseada em Projetos; Sala de Aula Invertida; Gamificação (OLIVEIRA; OLIVEIRA, 2021); Aprendizagem Baseada em Problemas (MACIEL et al., 2020; ROSSETO et al., 2021); Blended Learning ou Ensino Híbrido (ARRUDA; SIQUEIRA, 2020); Seminários (ARRUDA; SIQUEIRA, 2020; ASSIS; BARBOSA; REIS, 2021; ROSSETO et al., 2021); Eventos Online; Tarefas Assíncronas (REGUEIRO et al., 2020).

Para potencializar a aplicação dessas metodologias, as instituições de ensino então investindo em apoio ao desenvolvimento de competências digitais aos docentes, para que os mesmos possam aplicar da melhor forma possível suas estratégias de ensino com o auxílio da $W e b$ 2.0 e TDIC. (BARBOSA; BRESSAN JR., 2020).

\subsection{Tipos de recursos educacionais digitais}

Com a implantação da prática educacional online e o objetivo de proporcionar aos alunos uma experiência de aprendizado e pesquisa mais enriquecedora nessa época de ensino remoto, professores tem adotado ou criado variados recursos educacionais digitais (RED) como ferramentas didáticas para utilizar em suas aulas no ambiente virtual.

Os RED, que são entendidos como arquivos ou mídias digitais, foram muito importantes paras as aulas remotas. Dentre eles, os mais criados ou utilizados foram: arquivos ou documentos em PDF (MEDEIROS et al., 2020; VALENTE et al., 2020); artigos (FERREIRA et al., 2020); áudios (GALVÃO et al., 2021; LIMEIRA; BATISTA; BEZERRA, 2020); aulas ministradas ao vivo (síncrona) e/ou gravadas para utilização assíncrona (OLIVEIRA; OLIVEIRA, 2021; ROSSETO et al., 2021); aplicativos (GALVÃO et al., 2021; GUSSO; CASTRO; SOUZA, 2021); curso online (REGUEIRO et al., 2020); hipertextos; simulação clínica em ambiente virtual; (GUSSO; CASTRO; SOUZA, 2021); games serious e jogos didáticos (OLIVEIRA; OLIVEIRA, 2021); quirzes e questionários (REGUEIRO et al., 2020; BARBOSA; BRESSAN JR., 2020); laboratório remoto (AMARAL; POLYDORO, 2020); lives (SILUS; FONSECA; JESUS, 2020; REGUEIRO et al., 2020; FERREIRA et al., 2020); microvídeos (ASSIS; BARBOSA; REIS, 2021); oficinas virtuais (AMARAL; POLYDORO, 2020); podcasts ( LIMEIRA; BATISTA; BEZERRA, 2020; REGUEIRO et al., 2020; AMARAL; POLYDORO, 2020); portfólios (FERREIRA et al., 2020; 
MACIEL et al., 2020); simulações de realidade virtual e realidade aumentada (GALVÃO et al., 2021; SANTOS et al, 2021; ASSIS; BARBOSA; REIS, 2021); slides (SANTOS et al, 2021); teleconferências (ASSIS; BARBOSA; REIS, 2021; AMARAL; POLYDORO, 2020); vídeos e videoaulas (MACIEL et al., 2020; GALVÃO et al., 2021; FERREIRA et al., 2020; REGUEIRO et al., 2020; ARRUDA; SIQUEIRA, 2020; ASSIS; BARBOSA; REIS, 2021); videoconferências gravadas (OLIVEIRA; OLIVEIRA, 2021; MACIEL et al., 2020; MEDEIROS et al., 2020); webinars (ASSIS; BARBOSA; REIS, 2021; FERREIRA et al., 2020).

É importante ressaltar que a implementação de cada uma dessas estratégias didáticas identificadas envolve a utilização de materiais de apoio. Esses materiais didáticos ou de apoio, também conhecidos como RED, podem ser produzidos pelo próprio professor ou selecionados a partir de um processo de curadoria digital de conteúdos, que envolve a gestão atuante e a preservação de recursos digitais durante todo o ciclo de vida (MÁRDERO ARELLANO, 2008; SAYÃO; SALES, 2012).

Esses RED são criados com apoio de ferramentas informatizadas, e disponibilizados aos alunos através dos Ambientes Virtuais de Aprendizagem (AVA), repositórios de objetos educacionais, redes sociais entre outras plataformas digitais. Tais ferramentas de produção de RED serão abordadas na próxima subseção.

\subsection{Ferramentas de produção de recursos educacionais digitais}

Os RED são criados e disponibilizados com a utilização de algumas ferramentas ou plataformas. As plataformas de autoria permitem a criação/produção de RED pelos professores, algumasdelas também funcionam como repositórios e permitem a disponibilizaçãodireta aos alunos direta aos alunos. Um exemplo disso é a ferramenta Canva ${ }^{1}$, que possibilita a criação de tipos variados de RED e seu compartilhamento com os alunos.

Entre as ferramentas de autoria e produção de RED estão: Figma, que é uma plataforma baseada na nuvem e no local, cria designs e compartilha protótipos (ARRUDA; SIQUEIRA, 2020); Lucidchart, que é um aplicativo de diagramação online, onde são produzidos organogramas, fluxogramas, mapas mentais, workflow etc (ROSSETO et al., 2021). Tem sido usado também o Screencastify, que é uma extensão que permite aos seus usuários criar capturas em vídeo da tela da aba atual do Google Chrome. De maneira rápida e prática, ele pode gravar os vídeos com resolução pré-definida e permite armazenar as gravações no Google Drive ou no próprio plugin (CARNEIRO et al., 2020).

\footnotetext{
${ }^{1}$ Disponível em: https://www.canva.com/pt_br/
} 
As redes sociais também são utilizadas como meio de produção de RED. Dentre elas destacam-se: Whatsapp (SILVA; FREITAS, 2020; VALENTE et al., 2020; LIMEIRA; BATISTA; BEZERRA, 2020; FERREIRA et al., 2020); Youtube (REGUEIRO et al., 2020; CARNEIRO et al., 2020); Facebook (VALENTE et al., 2020; REGUEIRO et al., 2020; CARNEIRO et al., 2020; GONÇALVES; GAMBARATO, 2020); Telegram (VALENTE et al., 2020); Instagram (ARRUDA; SIQUEIRA, 2020; SILUS; FONSECA; JESUS, 2020; REGUEIRO et al., 2020; VALENTE et al., 2020).

Dentre as ferramentas usadas para criar ou para compartilhar RED, algumas delas também são usadas na realização de aulas remotas, como será mostrado na próxima subseção.

\subsection{Plataformas digitais para aulas remotas}

Os meios utilizados para a transmissão de aulas e compartilhamento de RED nesse momento de ensino remoto emergencial tem sido as plataformas digitais, as quais têm sido adotadas por professores como forma de viabilizar o ensino. Segundo a revisão integrativa realizada, as principais plataformas usadas na realização de aulas remotas foram os Ambientes Virtuais de Aprendizagem (AVA), redes sociais e softwares de webconferência.

Os AVA são denominaçõesutilizadas para softwares desenvolvidos para o gerenciamento

do ensino via $W e b$. São plataformas que possuemfuncionalidades mais completas no que diz respeito a gestão de cursos e disciplinas, tais como: configuração das estratégias didáticas remotas, disseminação e compartilhamento de RED como materiais didáticos ou de apoio, recursos de interação e comunicação, recursos avaliativos e de monitoramento da participação de alunos. Tratam-se, portanto, de espaços onde seres humanos interagem entre si e com objetos de aprendizagem, potencializando assim, a construção individual ou colaborativa do conhecimento (RIBEIRO; TODESCAT; JACOBSEN, 2015; SCHLEMMER, 2002).

Segundo a pesquisa realizada, dentre os AVA mencionados destacam-se: Edmodo (CARNEIRO et al., 2020); Google Classroom (GUSSO; CASTRO; SOUZA, 2021; GONÇALVES; GAMBARATO, 2020; MÉLO et al., 2020; FERREIRA et al., 2020; SILUS; FONSECA; JESUS, 2020); Moodle (GUSSO; CASTRO; SOUZA, 2021); Blackboard (BOELL; ARRUDA, 2020).

Sem dúvida os AVA têm tido uma fundamental importância na condução das aulas remotas. Por intermédio deles são desenvolvidas estratégias didáticas assíncronas, são compartilhados RED, são realizadas e entregues as atividades pelos alunos nas aulas remotas. 
Em alguns dos artigos, os autores mencionam a ferramenta Canva como sendo um AVA (GONÇALVES; GAMBARATO, 2020; BOELL; ARRUDA, 2020). De fato, Nobre (2020) afirma que

\begin{abstract}
Os AVA propiciam a criação de salas de aulas virtuais e são projetados para permitir o compartilhamento dos recursos, a colaboração entre os participantes, o compartilhar de conhecimentos, o acesso a tutores, o acesso a banco de dados, simulações entre outros.
\end{abstract} (NOBRE, 2013, p. 26).

Tal definição, se considerada, de fato até justificaria a categorização do Canva como um AVA. Entretanto, como essa ferramenta não oferece todas as funcionalidades necessárias à gestão de cursos e disciplinas remotas, então ela não deveria ser classificada como AVA, levando-se em conta sua aplicação típica no contexto da EaD.

Dentre as ferramentas de comunicação síncrona, que permite a conexão entre as pessoas por webconferência, mensagens de texto e chamadas de áudio e vídeo, a mais utilizada foi o Google Meet. A possibilidade de qualquer pessoa com uma conta Google poder criar uma reunião online com até 100 participantes e duração de até 60 minutos, provavelmente justifica uma maior preferência por essa plataforma (LIMEIRA; BATISTA; BEZERRA, 2020; VALENTE et al., 2020; MÉLO et al., 2020; ARRUDA; SIQUEIRA, 2020; FERREIRA et al., 2020; BOELL; ARRUDA, 2020; CARNEIRO et al., 2020; SILUS; FONSECA; JESUS, 2020).

A ferramenta Webex também foi mencionada em alguns artigos (MACIEL et al., 2020; LIMEIRA; BATISTA; BEZERRA, 2020). Do Grupo Cisco, a Webex Meeting Center é uma plataforma de webconferência corporativa e foi uma das ferramentas também adotadas por instituições de ensino na realização de suas aulas remotas, possibilitando reuniões por áudio e vídeo em alta definição, e fornecendo serviços de sala de espera, de agendamento e de gravação de reuniões, de compartilhamento de telas e arquivos e de salvamento de informações sobre a reunião (registro do bate-papo e lista de pessoas que estiveram presentes).

Outra ferramenta adotada foi o Google Hangouts (BOELL; ARRUDA, 2020; GONÇALVES; GAMBARATO, 2020; MÉLO et al., 2020; CARNEIRO et al., 2020) que é uma plataforma de comunicação com mensagens instantâneas, chat de vídeo e voz e conversas em grupo.

O Zoom, que é um software de teleconferência de vídeo proprietário, permitindo a participação simultânea de 100 pessoas e com restrições de 40 minutos, também recebeu destaque nesse período de aulas remotas (SILUS; FONSECA; JESUS, 2020; BARBOSA; VIEGAS; BATISTA, 2020; GUSSO; CASTRO; SOUZA, 2021; ASSIS; BARBOSA; REIS, 2021). 
Outra ferramenta utilizada nesse período foi o Microsoft Teams, que é uma plataforma unificada de comunicação e colaboração que combina bate-papo, videoconferências entre outros serviços (BARBOSA; VIEGAS; BATISTA, 2020; CARNEIRO et al., 2020; FERREIRA et al., 2020; GUSSO; CASTRO; SOUZA, 2021).

Outras plataformas de comunicação síncrona adotadas nesse período foram: BigBlueButton (REGUEIRO et al., 2020; MÉLO et al., 2020); Skype for Business (SILUS; FONSECA; JESUS, 2020; GUSSO; CASTRO; SOUZA, 2021); Jitsi Meet (MÉLO et al., 2020; LIMEIRA; BATISTA; BEZERRA, 2020); Mconf (GONÇALVES; GAMBARATO, 2020), que é o serviço de webconferência da Rede Nacional de Ensino e Pesquisa (RNP), permitindo comunicação em tempo real entre múltiplas pessoas com compartilhamento de áudio, vídeo, apresentações, tela, entre outros conteúdos. Esses ambientes virtuais em conjunto com a Internet e com as Tecnologias Digitais de Informação e Comunicação são vitais para a realização das aulas remotas.

\subsection{Preservação dos recursos educacionais digitais}

Durante a leitura dos artigos buscou-se descobrir como os professores estavam preservando os recursos educacionais digitais criados por eles. Onde eles estavam guardando esses recursos para seu reuso. Como resultado, verificou-se que somente um dos artigos analisados, das autoras Amaral e Polydoro (2020), abordou a temática de preservação desses recursos educacionais digitais criados para atender às demandas do ensino remoto. Segundo as autoras, "as plataformas educacionais são frequentemente usadas para repositório de conteúdo, explorando-se pouco seus recursos de atividade e interação, que devem caracterizar o ensino remoto" (AMARAL; POLYDORO, 2020). Assume-se, pela afirmação das autoras, que o próprio AVA funcionaria como repositório dos RED desenvolvidos no ensino remoto. Isto, todavia, é bastante preocupante, levando-se em conta que essas plataformas não necessariamente possuem mecanismos de busca e recuperação dos recursos depositados com vistas ao reuso em cursos e disciplinas futuras, nem tampouco há garantias de que possuem funcionalidades especializadas para implementar o ciclo de vida da curadoria de conteúdos (MÁRDERO ARELLANO, 2008; SAYÃO; SALES, 2012).

Percebeu-se que a temática sobre preservação de recursos educacionais digitais criados para atender às demandas do ensino remoto emergencial ainda não está sendo abordada na literatura analisada. Talvez, por conta da rapidez com que esse novo formato de ensino surgiu, ainda não houve tempo hábil para que se pudesse explorar tal questão de pesquisa.

Por outro lado, isso significa que pesquisas e estudos futuros precisarão ser realizados com a intenção de abordar as formas de preservação desses recursos, tais como videoaulas, e-books, $p d f$, 
podcast, wikis, portfólios, webconferências, tutoriais, dentre outros. Esses recursos precisam ser preservados para reuso, mas como e onde eles podem ou devem ser preservados? Pergunta que fica aberta para futuras pesquisas.

\section{Conclusão}

A pesquisa, que teve como objetivo analisar o ensino remoto emergencial e o uso das tecnologias que o viabilizam no contexto das Instituições de Ensino Superior por meio de uma revisão integrativa, constatou que a adoção desse novo formato de ensino trouxe mudanças bruscas na vida de professores e de alunos.

Verificou-se através desta pesquisa que a transição do ensino presencial para o ensino digital por conta da pandemia da Covid-19 foi e ainda está sendo muito desafiadora, pois a inserção das tecnologias necessárias ao ensino remoto mostrou-se eficiente por trazer mais dinamicidade às aulas, mas também se apresentou como empecilho para os menos favorecidos em letramento digital e/ou em condições financeiras de ter e acessar as devidas ferramentas de forma igualitária.

Dentre os benefícios estão a dinamicidade que o uso das TDIC representa para o ensino remoto, a rapidez e facilidade dos encontros síncronos e assíncronos, o conhecimento de várias plataformas utilizadas para a realização de aulas e compartilhamentos de recursos educacionais digitais, além de mensagens instantâneas, áudios, vídeos, jogos, webconferências e muita interação entre alunos e professores, tudo isso proporcionado pelo uso das tecnologias.

Conclui-se com isso que o ensino remoto emergencial tem sido um dinâmico e ao mesmo tempo desafiador modelo de ensino, e que as Instituições de Ensino Superior, assim como seus professores e alunos, têm se esforçado bastante para adquirir os recursos e as competências necessárias, inclusive a digital, para dar continuidade às suas atividades acadêmicas da melhor forma possível. Destarte, para que se obtenha os resultados esperados, a definição adequada das estratégias didáticas e das plataformas virtuais, bem como a seleção/criação e preservação dos recursos educacionais digitais utilizados, são ações fundamentais.

Curiosamente, não foram encontrados na presente revisão integrativa elementos significativos sobre aspectos relacionados à preservação dos RED produzidos no ensino remoto emergencial, o que sugere a necessidade de desenvolvimento de novas pesquisas a esse respeito. 


\section{Referências}

ALVES, L. Educação remota: entre a ilusão e a realidade. Interfaces Cientificas, Aracaju, v. 8, n. 3, p.348-365, 2020. https://doi.org/10.17564/23163828.2020v8n3p348-365 Disponível em: https://periodicos.set.edu.br/educacao/article/view/9251 Acesso em: 14 jul. 2021.

BEHAR, P. A. O ensino remoto emergencial e a Educação a Distância. JU Jornal da Universidade Federal do Rio Grande do Sul. Porto Alegre, 2 jul. 2021. Disponível em:

https://www.ufrgs.br/jornal/o-ensino-remoto-emergencial-e-a-educacao-a-distancia/ Acesso em: 14 jul. 2021.

BERNARDO, K.A. da S.; MAIA, F.L.; BRIDI, M.A. As configurações do trabalho remoto da categoria docente no contexto da pandemia COVID-19. NORUS Novos Rumos Sociológicos, v. 8, n. 14, p. 8-39, ago./dez. 2020. https://doi.org/10.15210/norus.v8i14.19908 Disponível em: https://periodicos.ufpel.edu.br/ojs2/index.php/NORUS/article/view/19908 Acesso em: 25 jun. 2021.

BRASIL. Ministério da Educação. Portaria n ${ }^{0} 343$, de 17 de março de 2020. Dispõe sobre a substituição das aulas presenciais por aulas em meios digitais enquanto durar a situação de pandemia [...]. Brasília, DF: Gabinete do Ministro, [2020]. Disponível em:

https://www.in.gov.br/en/web/dou/-/portaria-n-343-de-17-de-marco-de-2020-

248564376 Acesso em 20 jun. 2021.

BRASIL. Ministério da Educação. Portaria $N^{0} 544$, de 16 de junho de 2020. Dispõe sobre a substituição das aulas presenciais por aulas em meios digitais, enquanto durar a situação de pandemia [...]. Brasília, DF: Gabinete do Ministro, [2020]. Disponível em:

https://www.in.gov.br/en/web/dou/-/portaria-n-544-de-16-de-junho-de-2020-261924872 Acesso em: 20 jun. 2021.

BRASIL. Ministério da Educação. Conselho Pleno. Conselho Nacional de Educação. Parecer CNE/CP n $n^{\circ}$ 5/2020. ASSUNTO: Reorganização do Calendário Escolar e da possibilidade de cômputo de atividades não presenciais [...] Brasília, DF: Ministério da Educação, 28 abr. 2020. Disponível em: http://portal.mec.gov.br/index.php?option= com_docman \& view=download alias=14511-pcp005-20 \& category_slud=marco-2020-pdf \& Itemid=30192 Acesso em: 13 jul. 2021.

BRASIL. Ministério da Saúde. Portaria $n^{\circ} 188$, de 3 de fevereiro de 2020. Declara Emergência em Saúde Pública de importância Nacional [...]. Brasília, DF: Gabinete do Ministro, [2020]. Disponível em: https://www.in.gov.br/en/web/dou/-/portaria-n-188-de-3-de-fevereiro-de2020-241408388 Acesso em: 12 jul. 2021.

BRASIL. Presidência da República. Lei n 13.979, de 06 de fevereiro de 2020. Dispõe sobre as medidas para enfrentamento da emergência de saúde pública [...]. Brasília, DF: Secretaria-Geral. Subchefia para Assuntos Jurídicos, [2020]. Disponível em: http://www.planalto.gov.br/ccivil_03/_ato2019-2022/2020/lei/113979.htm\# Acesso em: 12 jul. 2021 
BRASIL. Presidência da República. Lei ñ 14.040, de 18 de agosto de 2020. Estabelece normas educacionais excepcionais a serem adotadas durante o estado de calamidade pública [...]. Brasília, DF: Secretaria-Geral. Subchefia para Assuntos Jurídicos, [2020]. Disponível em: http://www.planalto.gov.br/ccivil_03/_ato2019-2022/2020/Lei/L14040.htm Acesso em: 13 jul. 2021.

BRASIL. Presidência da República. Medida provisória $n^{\circ}$ 934, de $1^{\circ}$ de abril de 2020. estabelece normas excepcionais sobre o ano letivo da educação básica e do ensino superior [...]. Brasília, DF: Secretaria-Geral. Subchefia para Assuntos Jurídicos, [2020]. Disponível em: http://www.planalto.gov.br/ccivil_03/_ato2019-2022/2020/Mpv/mpv934impressao.htm Acesso em: 13 jul. 2021.

BRASIL. Presidência da República. Decreto $n^{\circ}$ 9.057, de 25 de maio de 2017. Regulamenta o art. 80 da Lei $n^{\circ}$ 9.394, de 20 de dezembro de 1996, que estabelece as diretrizes e bases da educação nacional. Brasília, DF: Secretaria-Geral. Subchefia para Assuntos Jurídicos, [2017]. Disponível em: http://www.planalto.gov.br/ccivil_03/_Ato2015-2018/2017/Decreto/D9057.htm\#art24 Acesso em: 15 dez. 2021.

HODGES, C.B. et al. A diferença entre ensino remoto de emergência e aprendizagem online. Educause Review, mar., 2020. Disponível em:

https://www.researchgate.net/publication/340535196_The_Difference_Between_Emergency_R emote_Teaching_and_Online_Learning Acesso em: 13 jul. 2021.

HOFFMANN, G. Precisamos revisar o ensino remoto. Metodologias de Ensino. Opinião. Portal Desafios da Educação. 17 dez. 2020. Disponível em:

https://desafiosdaeducacao.grupoa.com.br/revisar-ensino-remoto-2021/ Acesso em: 14 jul. 2021.

MÁRDERO ARELLANO, M.Á. Critérios para a preservação digital da informação científica. 2008. Tese (Doutorado em Ciência da Informação) - Universidade de Brasília, Brasília, 2008. Disponível em: https://repositorio.unb.br/handle/10482/1518 Acesso em: 16 dez. 2021.

MARTINS, H.F.S. A Intermitência dos tempos que correm. In: ALVES, J.M; CABRAL, I. (Eds.). Ensinar e aprender em tempo de COVID-19: entre o caos e a redenção. Prefácio João Costa, Porto: Ed. Faculdade de Educação e Psicologia da Universidade Católica Portuguesa, maio, 2020. E-Book. Disponível em:

https://www.fep.porto.ucp.pt/sites/default/files/files/FEP/SAME/Ebook_Ensinar_e_aprende r_em_tempos_de_COVID_19.pdf?fbclid=IwAR0Kgfz1-c9-Qk6Z1-

OpG1405Gu4hyLb8w3e8JnuA2hnbuxYQBypW72jBaw Acesso em: 14 jul. 2021.

MATTAR, J. Resistências e aprendizados em EaD durante a pandemia. Jornal da Universidade Federal do Rio Grande do Sul, Porto Alegre, 10 set. 2020. Disponível em: https://www.ufrgs.br/jornal/resistencias-e-aprendizados-em-ead-durante-a-pandemia/ Acesso em: 14 jul. 2021.

MENDES, K.S, SILVEIRA; R.C.C.; GALVÃO, C.M. Revisão integrativa: método de pesquisa para a incorporação de evidências na saúde e na enfermagem. Texto \& Contexto Enfermagem, Florianópolis, v. 17, n. 4, p. 758-764, out./dez. 2008. Disponível em: https://www.scielo.br/j/tce/a/XzFkq6tjWs4wHNqNjKJLkXQ/?format=pdf\&lang=pt Acesso em: 28 jun. 2021. 
MOREIRA, J.AM.; HENRIQUES, S.; BARROS, D.M. Vieira. Transitando de um ensino remoto emergencial para uma educação digital em rede, em tempos de pandemia.

http:/ / dx.doi.org/10.5585/Dialogia.N34.17123 Disponível em:

https://repositorioaberto.uab.pt/handle/10400.2/9756 Acesso em: 14 jul. 2021.

MOREIRA, J.AM.; SCHLEMMER, E. Por um novo conceito de educação e paradigma de educação digital onlife. Revista UFG, v. 20, p. 1-35, 2020.

https://doi.org/10.5216/revufg.v20.63438 Disponível em:

https://www.revistas.ufg.br/revistaufg/article/view/63438/36079 Acesso em: 14 jul. 2021.

NOBRE, I.A.M. Docência coletiva: saberes e fazeres na Educação a Distância. 2013. Tese

(Doutorado em Educação) - Programa de Pós-Graduação em Educação, Universidade Federal do Espírito Santo, Centro de Educação, Vitória, 2013. Disponível em:

http://repositorio.ufes.br/handle/10/2169 Acesso em: 16 dez. 2021.

OLIVEIRA, G.S.; MENDONÇA, J.A.; SILVA, L.A. Metodologias ativas e TDICs: experiência no ensino remoto. Cadernos da Fucamp, v. 20, n. 46, p.147-160, 2021. Disponível em:

https://www.fucamp.edu.br/editora/index.php/cadernos/article/viewFile/2471/1541 Acesso em: 14 jul. 2021.

ORTEGA, A. Atenção à saúde mental é imprescindível para aproveitamento no ERE.Jornal da Universidade da UFRGS, 3 de setembro de 2020. Disponível em:

http://www.ufrgs.br/ufrgs/noticias/atencao-a-saude-mental-e-imprescindivel-paraaproveitamento-no-ere Acesso em: 14 jul. 2021.

OSÓRIO, A.J. Reflexões sobre tecnologia e educação em tempo de pandemia. In: A Universidade do Minho em tempos de pandemia. Porto: Uminho Editora , p. 213-224. nov. 2020.

http://http://10.0.85.54/uminho.ed.24.9 Disponível em:

http://repositorium.sdum.uminho.pt/handle/1822/70228 Acesso em: 14 jul. 2021.

RIBEIRO, F.B.V.; TODESCAT, M.; JACOBSEN, A.L. Avaliação de ambientes virtuais de aprendizagem: uma reflexão sobre o modelo interacionista e construtivista. Revista Renove Novas Tecnologias na Educação, v. 13, n. 2, 2015. DOI: https://doi.org/10.22456/1679-1916.61396 Disponível em: https://seer.ufrgs.br/renote/article/view/61396 Acesso em: 16 dez. 2021

RITTER, D.; PERIPOLLI, P.Z.; BULEGON, A.M.. Desafios da educação em tempos de pandemia: tecnologias e ensino remoto. Anais do CIET:EnPED:2020 - (Congresso

Internacional de Educação e Tecnologias Encontro de Pesquisadores em Educação a Distância), São Carlos, ago. 2020. Disponível em:

https://cietenped.ufscar.br/submissao/index.php/2020/article/view/1113 Acesso em: 25 jun. 2021.

SALDANHA, L.C.D. O discurso do ensino remoto durante a pandemia de COVID-19. Revista Educação e Cultura Contemporânea, v. 17, n. 50, p. 124-144, 2020. Disponível em: http://periodicos.estacio.br/index.php/reeduc/article/view/8701 Acesso em: 06 jul. 2021. 
SAYÃO, L.F.; SALES, L.F. Curadoria digital: um novo patamar para preservação de dados digitais de pesquisa. Informação \& Sociedade: Estudos, João Pessoa, v.22, n.3, p. 179-191, set./dez. 2012. Disponível em:

https://www.marilia.unesp.br/Home/Instituicao/Docentes/EdbertoFerneda/curadoria-digital--sayao.pdf Acesso em: 16 dez. 2021.

SCHLEMMER, E. AVA: um ambiente virtual de convivência interacionista sistêmico para comunidades virtuais na cultura da aprendizagem. 2002. Tese (Programa de Pós-Graduação em Informática na Educação) - Universidade Federal do Rio Grande do Sul, Porto Alegre. 2002. Disponível em: https://gpedunisinos.files.wordpress.com/2009/04/tese_eliane.pdf Acesso em: 16 dez. 2021.

SCHNEIDER, E.M. et al. O uso das tecnologias digitais da informação e comunicação (TDIC): possibilidades para o ensino (não) presencial durante a pandemia COVID-19. Revista Científica Educação, v. 4, n. 8, 2020. Dossiê: Educação em Tempos de Pandemia. https://doi.org/10.46616/rce.v4i8.123 Disponível em: https://periodicosrefoc.com.br/jornal/index.php/RCE/article/view/123 Acesso em: 26 jun. 2021.

SILVA, S.L.R.; ANDRADE, A.V.C.; BRINATTI, A.M. Ensino remoto emergencial. Ponta GrossaPR: Ed. dos Autores. Disponível em: http://www1.fisica.org.br/mnpef/sites/default/files/anexosnoticia/EnsinoRemotoEmergencial _SilvaAndradeBrinatti.pdf Acesso em: 14 jul. 2021.

SOUZA, M.T.; SILVA, M.D.; CARVALHO, R. X. Revisão integrativa: o que é e como fazer? Einstein. São Paulo, v. 8, n. 1, p.102-6, mar. 2010. http://dx.doi.org/10.1590/s167945082010 rw1134 Disponível em: https://journal.einstein.br/pt-br/article/revisao-integrativa-oque-e-e-como-fazer/ Acesso em 12 jul. 2021.

WORLD HEALTH ORGANIZATION. Timeline of WHO's response to the pandemic from 31 december 2019. WHO publishes interactive timeline of its response. 30 july 2020. Disponível em: https://www.who.int/emergencies/diseases/novel-coronavirus-2019/interactive-timeline Acesso em: 07 jul. 2021. 